\title{
Flow-Injection Electrospray Ionization Mass Spectrometry of Crude Cell Extracts for High-Throughput Bacterial Identification
}

\author{
Seetharaman Vaidyanathan, Douglas B. Kell, and Royston Goodacre \\ Institute of Biological Sciences, University of Wales, Aberystwyth, Ceredigion, Wales, United Kingdom
}

\begin{abstract}
Flow-injection electrospray ionization mass spectrometry (FI-ESI-MS) of unfractionated cellfree extracts obtained from bacterial cells suspended in a solvent mixture was investigated as a rapid analytical method for reproducible, high-throughput bacterial identification. Five bacterial strains (two Escherichia coli, two Bacillus spp. and one Brevibacillus laterosporus) were studied in this investigation. Axenically grown bacterial cells were suspended in an acidic organic solvent and the cell-free extract was sequentially injected into a solvent flow stream that was sprayed into the ionization chamber of the ESI-MS. The spectra produced contained reproducible information, which was useful for discriminating between the bacteria. Tandem mass spectrometry was used to characterize further the peaks, and at least three classes of macromolecules, namely phospholipids, glycolipids, and proteins, were found to contribute most to the spectral information. Bacterial extracts stored under different conditions gave very similar mass spectra for each of the five bacterial strains, indicating that the extracts were stable even at room temperature for up to $24 \mathrm{~h}$, with no loss of information content, which has obvious implications for automated high-throughput analysis. An analysis of the components of the extracting solvent mixture and their effects on the spectral information showed that acetonitrile contributes most significantly to the extraction process and hence to the information content of the spectra. (J Am Soc Mass Spectrom 2002, 13, 118-128) (c) 2002 American Society for Mass Spectrometry
\end{abstract}

$\mathrm{T}$ There is a continuing need for the development of methods that are rapid, reproducible, easy to operate, amenable to automation, and capable of high resolution, for the identification and characterization of microorganisms, especially for detecting biological hazards in food and the environment [1], in medical diagnosis [2], and in the screening of biotechnologically relevant metabolites [3]. Traditional microbiological methods in routine operation are time consuming, and can be labor intensive for specific biochemical characterization. Alternatively, mass spectrometry (MS) offers the potential to characterize populations based on chemotaxonomic biomarkers in a relatively more efficient manner [4].

For bacterial characterization using MS, early investigations involved the analysis of volatile fractions, especially by the application of pyrolysis MS [5, 6]. However, the highest $m / z$ value reproducibly attainable in the commonest pyrolysis MS instruments is very small (typically $<m / z 200$ ), moreover, due to the in vacuo thermal degradation step essentially all information on the structure or identity of the molecules pro-

Published online November 30, 2001

Address reprint request to Dr. S. Vaidyanathan, Cledwyn Building, Institute of Biological Sciences, University of Wales, Aberystwyth, Ceredigion SY23 3DD, Wales, UK. E-mail:ssv@aber.ac.uk ducing the pyrolysate is lost. Later, the application of desorption techniques, such as plasma desorption [7] and fast atom bombardment (FAB) [8,9], allowed the analysis of involatile fractions and extended the measurable mass range. The advent of "soft" ionization techniques, such as matrix-assisted laser desorption ionization (MALDI), and electrospray ionization (ESI) has enabled the mass spectrometric analysis of both large molecular weight compounds, such as proteins and nucleic acids [10,11], and low molecular weight metabolites [12], giving the potential for rapid characterization of microorganisms with greater accuracy, selectivity, and sensitivity for better discrimination. Consequently, the application of MALDI- and ESI-MS techniques for microbial classification and identification has been the subject of several investigations [13-15]. In particular, MALDI-MS of whole cells as a rapid means for microbial characterization is being widely investigated [15-18] because of its ability to characterize the proteome, albeit only a fraction of it, directly without 2-D gel electrophoretic separation and match these proteins to sequence databases [19].

However, as MALDI-MS techniques involve the mixing of a chemical matrix with the sample and the pulsed-firing of a laser to effect desorption and ionization of the analyte, they have matrix and laser associated problems that limit the scope of their general 
applicability to microbial characterization [13]. For instance, the dried sample matrix preparation is inhomogeneous, requiring the selection of "sweet" spots on the target that would give the best ion formation, and matrix adduct ions are often formed that decrease effective mass resolution and decrease the possibility of analyzing low $(\mathrm{m} / \mathrm{z}<1000)$ molecular weight species. Moreover, there are still concerns of spectral reproducibility, owing to the sample preparation steps [14, 17, 20, $21]$, although some investigations $[19,22,23]$ show that this problem can be overcome.

Alternatively, in ESI-MS which is being developed concurrently the samples are in the liquid phase, and ionization is carried out at atmospheric pressure, thus making it amenable to on-line automated integration with analyte separation techniques such as liquid chromatography (LC) and capillary electrophoresis (CE). This widens the scope of its applicability considerably. Indeed, ESI-MS has already been shown to be useful for microbial characterization, however, the introduction of bacteria has largely been via specific cell fractions or lysates; viz., phospholipids [24-26], lipopolysaccharides [27], lipooligosaccharides [28], muramic acids [29], and proteins $[30,31]$. Moreover, these have usually been presented to the ESI-MS after LC separation [12, 26, 29, 31].

Although the introduction of an analyte separation or sample clean-up step, such as LC [15], CE [27], or microdialysis [30] have been shown to produce clean and potentially informative spectra for microbial characterization, there have been few reports on the direct introduction of whole cells or cell free extracts without an analyte separation or clean-up step. Such an approach would be very useful for rapid characterization of microorganisms and would be attractive for highthroughput automated screening, if information rich spectra can be obtained. Intact viruses [32, 33] have been analyzed by ESI-MS. The ability of ESI-MS to provide information rich spectra, in both the positive and negative ion modes from whole bacterial suspensions, was first reported in 1999 [34], and this approach has subsequently been shown to be useful in discriminating a large number of endospore forming bacteria [35].

In the present study, we investigate the possibility of analyzing cell-free extracts by using flow-injection electrospray ionization mass spectrometry (FI-ESI-MS) in an automated mode, without prior analyte separation. Axenically grown bacterial cells were suspended in an acidic organic solvent and the cell-free extract was sequentially injected into a solvent flow stream that was introduced into the ionization chamber of the ESI-MS. In our earlier investigation [35], we observed little difference between the ESI-MS spectra of whole cell suspensions and those of cell-free extracts. Thus cellfree extracts were used in this investigation because they would be more amenable to a flow-through operation and to automation. The prominent biomarkers observed in the crude extract spectra were characterized by tandem mass spectrometry (MS/MS). The stability of the extracts over time and the effect the
Table 1. The bacterial strains used in the study

\begin{tabular}{llc}
\hline Species & Strain & $\begin{array}{c}\text { Identifier on } \\
\text { dendrograms }\end{array}$ \\
\hline \hline Escherichia coli & HB101 & $\mathrm{a}$ \\
Escherichia coli & UB5201 & $\mathrm{b}$ \\
Bacillus sphaericus & DSM 28 & $\mathrm{c}$ \\
Bacillus licheniformis & NTCT 10341 & $\mathrm{d}$ \\
Brevibacillus laterosporus & NTCT 7579 & $\mathrm{e}$ \\
\hline
\end{tabular}

individual components of the solvent mixture has on the extraction process and in turn the information content of the spectra, were also investigated. For illustrative purposes, two strains of the Gram-negative bacterium Escherichia coli and three Gram-positive bacteria (Bacillus sphaericus, Bacillus licheniformis, and Brevibacillus laterosporus) were studied.

\section{Experimental}

The five bacterial strains (Table 1) were grown on LabM (Media and Consumables Suppliers, Bury, Manchester, UK) blood agar base plates, at $37^{\circ} \mathrm{C}$, for $16 \mathrm{~h}$. Vegetative cells were carefully harvested using sterile plastic loops and resuspended in water (HPLC grade, Fisher scientific, Leicestershire, UK), after washing them twice. An aliquot of the bacterial suspension was then added to the solvent (50:50::acetonitrile: $0.2 \%$ formic acid, both supplied by Fisher Scientific) to give a final dry cell concentration of $0.5-1 \mu \mathrm{g} \mu \mathrm{l}^{-1}$. The mixture was vortex mixed for $30 \mathrm{~s}$ and centrifuged (17,000 g, $3 \mathrm{~min})$. The supernatant was then directly injected into the ESI mass spectrometer.

The stability of the supernatant for storage was determined at two time intervals and at two storage temperatures, namely after $5 \mathrm{~h}(t=5 \mathrm{~h})$ and overnight $(t=16-24 \mathrm{~h})$ storage, at room temperature $\left(20^{\circ} \mathrm{C}\right)$ and at $4{ }^{\circ} \mathrm{C}$, and compared to $t=0$.

The effect of the individual components of the solvent mixture on the relevant spectral information was determined by the protocol schematized in Figure 1. The bacterial suspensions (cells) were mixed with different constituent(s) of the solvent, and centrifuged to give the supernatants $(A-E)$, appropriate aliquots of which were mixed with the remaining components of the solvent mixture and injected into the ESI mass spectrometer.

\section{Flow-Injection ESI-MS}

FI-ESI-MS was performed using a QToF mass spectrometer, supplied by Micromass Ltd. (Wythenshawe, Manchester, UK). Spectra were acquired in the positive $(\mathrm{ES}+)$ ion mode. The crude cell-free extracts were introduced into the mass spectrometer, using the autosampler of a Waters 2790 (Waters Corporation, Milford, MA) liquid chromatography separation unit (without the column). A mobile liquid phase of $50 \%$ aqueous acetonitrile containing $10 \mathrm{mM}$ formic acid, was injected into the mass spectrometer at a flow rate of $50 \mu \mathrm{l}$ $\min ^{-1}$, and an aliquot $(50 \mu \mathrm{l})$ of the sample was loaded 


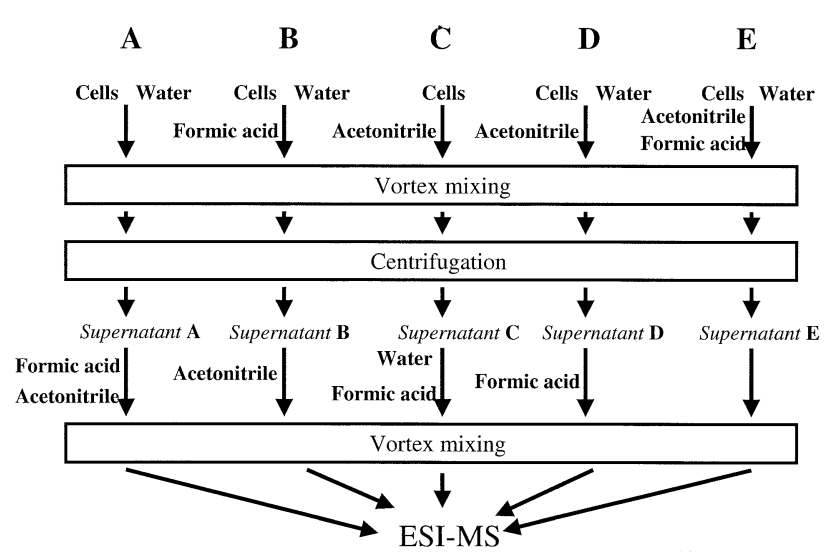

Figure 1. A schematic of the protocol adopted for determining the influence of solvent composition on the bacterial extraction and in turn the spectral signal. Five different treatments (A-E) were carried out to generate five supernatants, which were then injected directly into the ESI mass spectrometer.

from a $300 \mu \mathrm{l} 96$ well microtitre plate maintained at $4{ }^{\circ} \mathrm{C}$, directly into the flow stream and on into the ionization source of the mass spectrometer. Alternatively, samples (for MS/MS and for stability check) were introduced into the mass spectrometer using a $100 \mu$ l Hamilton gastight 1700 series syringe (Reno, NV) and a Harvard Apparatus Pump at a flow rate of $5 \mu \mathrm{min}^{-1}$.

The mass spectrometer was operated at a capillary voltage of $3200 \mathrm{~V}$; the extraction cone voltage was maintained at $10 \mathrm{~V}$ and the sample cone voltage was kept at either 40 or $80 \mathrm{~V}$, giving a cone potential of 30 or $70 \mathrm{~V}$, respectively. The spectra were acquired for both the cone potentials. The source and desolvation temperatures were maintained at $80^{\circ} \mathrm{C}$ and $150{ }^{\circ} \mathrm{C}$, respectively, while the desolvation and nebulizer gas flow rates were kept at $375 \mathrm{Lh}^{-1}$ and $20 \mathrm{Lh}^{-1}$, respectively. The ions were analyzed using the reflectron time-offlight (TOF) analyzer, and the mass range was set to 200-2000 m/z. For MS/MS investigations, argon was employed as the collision gas and the collision energy was set at 30-60 eV, and both the quadrupole $(\mathrm{Q})$ and TOF analyzers were employed, other conditions being the same as for the MS analysis.

Before acquiring the bacterial spectra, the instrument was calibrated using sodium trifluoroacetate [36] such that nominal mass measurement was achieved over the entire mass range $(\mathrm{m} / \mathrm{z} 200-2000)$. A mass accuracy of 5-10 ppm was recorded for the standard, at a mass resolution of 4000 FWHM over the acquired mass range. The calibration was carried out every day and was found to be stable for acquisitions over the day.

\section{Data Analysis}

The mass spectral data were acquired using the MassLynx software (version 3.4, provided by Micromass), running under Microsoft Windows NT on an IBM-compatible PC. The acquired data were exported for analysis to Matlab (version 5.3, supplied by The MathWorks Inc.,
Natick, MA), which also runs under Microsoft Windows NT on an IBM-compatible PC. Before analyses the spectral data were normalized to percent total ion count, and the analysis was carried out at atomic mass unit resolution.

The spectra were acquired in triplicates, and the replicate spectra were averaged. In order to minimize noise due to variations between replicate measurements, the variance between the triplicate spectra was subtracted from the average spectrum, using the following formula:

$$
\mathbf{S}=\mathbf{A}(1-(\mathbf{V} / \mathbf{A}))
$$

where $\mathbf{S}$ is the matrix of variance-corrected average spectrum, $\mathbf{A}$ is the average spectrum, and $\mathbf{V}$ is the matrix of variance of the replicate measurements.

The treatment in effect subtracts the variance due to replicate measurements from the average spectrum. The variance corrected average spectra were then used for assessing changes in the spectral information. Cluster analysis was employed and was carried out as detailed elsewhere [37, 38]. The initial stage involved the reduction of the dimensionality of the MS data by principal components analysis (PCA). The first few principal component (PC) scores that explained at least $95 \%$ of the total variance in the data were used for hierarchical cluster analysis (HCA). In HCA, the Euclidean distance between group centers in PCA space was used to construct a similarity measure, with the Gower similarity coefficient $S_{\mathrm{G}}$. Then an agglomerative clustering algorithm was employed to process these distance measures to construct a dendrogram. The dendrogram is a tree diagram that in this case gives the relative similarity level between the analyzed spectra, those clustering together being more similar to each other compared to those clustering away.

\section{Results and Discussion}

\section{FI-ESI Mass Spectra of Crude Extracts and Biomarker Characterization Using Tandem Mass Spectrometry}

The typical FI-ESI mass spectra of the crude extracts for the five microorganisms, acquired at the two cone potentials of 30 and $70 \mathrm{~V}$ are shown in Figure 2. The choice of the two cone potentials originates from our earlier investigation on the influence cone potential has on the mass spectra of bacterial suspensions [35]. On visual inspection alone, peaks that can be used for discrimination purposes can be identified at both the cone potentials. The prominent signals for four of the five bacteria can be seen between $\mathrm{m} / \mathrm{z} 500$ and 800 units. In addition, E. coli is characterized by a series of signals around $m / z 1400$, separated by 14 mass units, that are likely due to cell membrane phospholipids, as noted previously with intact cell ESI-MS [34]. There is also a series of peaks between $\mathrm{m} / \mathrm{z} 1300$ and 1400 that differ in relative intensities in the spectra of $B$. sphaericus and $B r$. laterosporus, but absent in the B. licheniformis spectrum. 

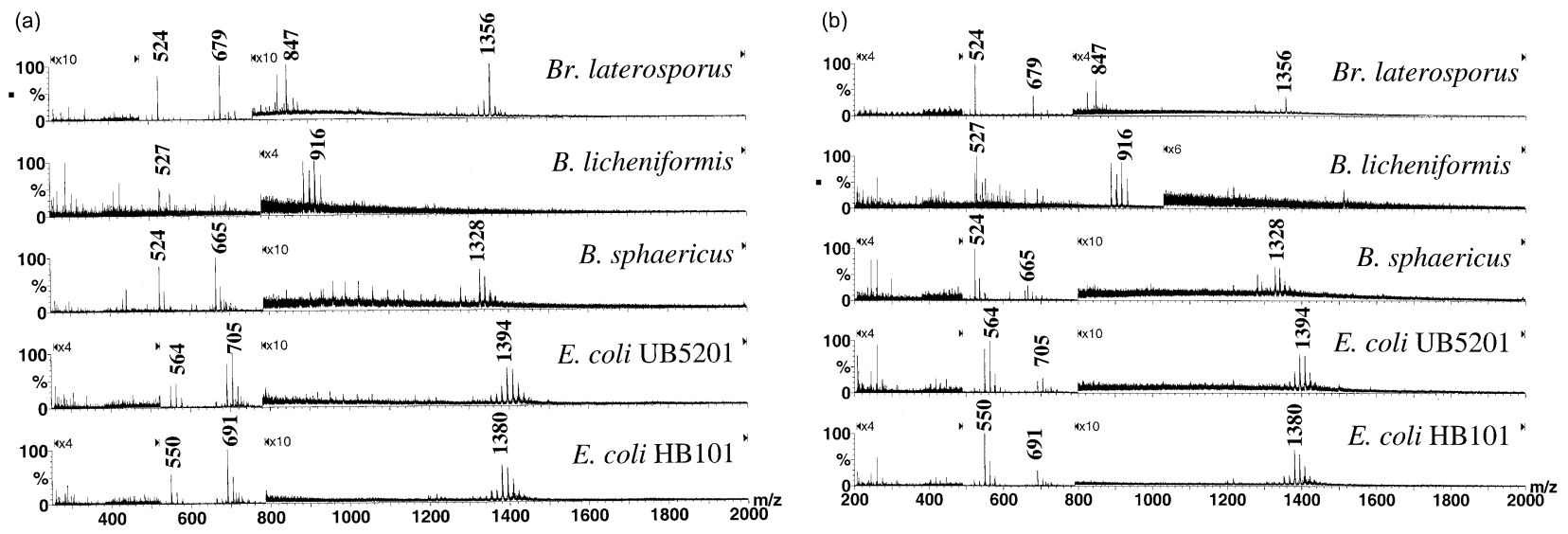

Figure 2. Typical positive ion ESI mass spectra of crude cell-free extracts prepared from whole cell suspensions of the five bacterial strains (Table 1), and acquired with a sample/skimmer cone potential of (a) $30 \mathrm{~V}$ and (b) $70 \mathrm{~V}$. Selected regions of the spectrum are magnified (with the magnification factor indicated where relevant), and some prominent peaks labeled, for ease of visualization. The ordinates are the percent relative intensities.

B. sphaericus is also characterized by a charge distribution between $\mathrm{m} / \mathrm{z} 800$ and 1300 , at $30 \mathrm{~V}$ cone potential. A similar charge distribution, although not as prominent, can be seen in the E. coli UB5201 spectrum at $30 \mathrm{~V}$ cone potential. Increasing the cone potential to $70 \mathrm{~V}$ resulted in a relative increase in the signal intensity of certain peaks. For instance, the peaks between $\mathrm{m} / \mathrm{z} 500$ and 600 in the spectra of four of the five bacteria, can be seen to increase in relation to the peaks between $\mathrm{m} / \mathrm{z} 600$ and 700 , and this effect can be attributed to collision induced fragmentation. For B. licheniformis, the relative spectral intensity of the characteristic peaks around $\mathrm{m} / \mathrm{z} 900$ increases with an increase in the cone potential. However, for B. sphaericus, the characteristic charge distribution between $\mathrm{m} / \mathrm{z} 800$ and 1300 disappears on increasing the cone potential to $70 \mathrm{~V}$.

In order to identify the biochemical origin of the prominent peaks, MS/MS was carried out on selected peaks. Table 2 lists the fragmentation patterns observed for the selected peaks for each of the five bacteria (details of the MS/MS conditions are given above). The fragmentation patterns of the prominent peaks in the $m / z$ 500-800 region are suggestive of phospholipids since similar patterns have been observed using FAB on bacteria $[8,9,39]$ and ESI-MS on bacterial phospholipids [24]. For example, the peak at $\mathrm{m} / \mathrm{z} 705$ in the E. coli UB5201 spectrum is separated by 141 mass units from another prominent peak at $\mathrm{m} / \mathrm{z} 564$, the latter appearing as a product ion in MS/MS when the precursor ion at $\mathrm{m} / \mathrm{z} 705$ is fragmented (Table 2). The difference of 141 mass units is likely to correspond to a neutral loss of the polar head group (ethanolaminephosphate) from the protonated phosphotidylethanolamine (PE) $(\mathrm{m} / \mathrm{z}$ 705) that has two acyl side chain lipids with a total of 33

Table 2. Tandem mass spectrometric (MS/MS) fragmentation patterns (product ions) at the listed collision energy for the most prominent peaks (precursor ions) observed in the FI-ESI mass spectra of the five bacterial species studied ${ }^{a}$

\begin{tabular}{|c|c|c|c|c|c|c|c|c|c|c|c|c|c|c|c|}
\hline Bacteria & $\begin{array}{l}\text { Precursor } \\
\text { ion }(\mathrm{m} / \mathrm{z})\end{array}$ & $\begin{array}{c}\text { Collision } \\
\text { energy } \\
(\mathrm{eV})\end{array}$ & & & & & & Produ & ions & $m / z)$ & & & & & \\
\hline \multirow[t]{3}{*}{ Br. laterosporus } & 1356 & 30 & 1356 & 679 & 524 & & & & & & & & & & \\
\hline & 679 & 30 & 524 & 225 & 207 & 151 & 137 & 123 & 109 & 95 & 81 & 71 & & & \\
\hline & 524 & 30 & 524 & 137 & 123 & 109 & 95 & 81 & 71 & & & & & & \\
\hline \multirow[t]{5}{*}{ B. licheniformis } & 932 & 50 & 932 & 741 & 689 & 661 & 645 & 574 & 527 & 405 & 365 & 299 & 214 & 199 & 113 \\
\hline & 916 & 60 & 916 & 674 & 645 & 483 & 405 & 356 & 347 & 299 & 127 & 85 & & & \\
\hline & 904 & 60 & 904 & 818 & 661 & 647 & 405 & 365 & 347 & 214 & 127 & 85 & & & \\
\hline & 888 & 60 & 888 & 645 & 483 & 405 & 365 & 347 & 299 & 145 & 127 & 85 & & & \\
\hline & 689 & 50 & 527 & 509 & 467 & 365 & 347 & 275 & 214 & 203 & 181 & 109 & 95 & & \\
\hline \multirow[t]{2}{*}{ B. sphaericus } & 1328 & 30 & 1328 & 665 & 524 & 381 & 334 & 299 & 156 & & & & & & \\
\hline & 665 & 30 & 665 & 524 & 495 & 428 & 348 & 299 & 268 & 207 & 151 & 137 & 123 & 111 & 95 \\
\hline \multirow[t]{3}{*}{ E. coli UB5201 } & 1394 & 30 & 1394 & 705 & 691 & 564 & 550 & 436 & 313 & & & & & & \\
\hline & 705 & 30 & 904 & 564 & 325 & 294 & 251 & 239 & 233 & 149 & 109 & 95 & 81 & & \\
\hline & 564 & 30 & 564 & 450 & 315 & 297 & 250 & 239 & 201 & 149 & 135 & 121 & 109 & 95 & \\
\hline \multirow[t]{2}{*}{ E. coli HB101 } & 1380 & 30 & 1380 & 691 & 677 & 564 & 550 & 436 & 280 & & & & & & \\
\hline & 691 & 30 & 691 & 550 & 313 & 280 & 239 & 219 & 165 & 137 & 109 & 95 & & & \\
\hline
\end{tabular}

${ }^{\text {aT }}$ The most abundant product ions are shown in bold. 


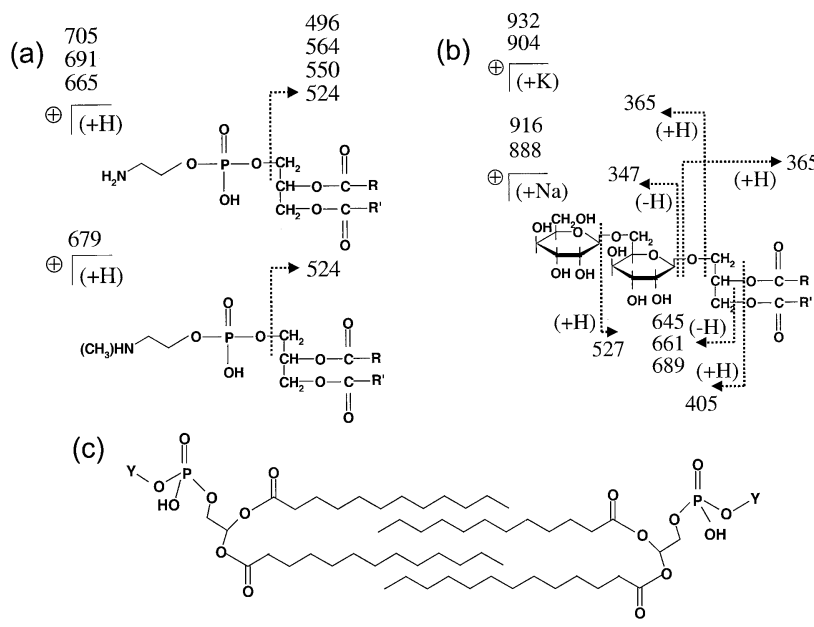

Figure 3. The chemical structures of the likely biomarkers observed in the ESI mass spectra of the crude bacterial extracts showing possible cleavage points (dotted arrows) that result in the listed $\mathrm{m} / \mathrm{z}$ peaks (listed numbers). $\mathbf{R}$ and $\mathrm{R}^{\prime}$ are the fatty acid side chains. The different numbers (peaks) for the same cleavage point result from differences in the chain length. (a) Phospholipids, (b) Glycolipids, and (c) Phospholipid cluster ( $\mathrm{Y}=$ polar head group) that is the probable origin of the signals in the $m / z 1300-1500$ region.

carbon atoms and possibly one unsaturation (C33:1), to give the molecular ion at $\mathrm{m} / \mathrm{z} 564$. Detachment of the polar head group from the rest of the phospholipid (Figure 3a) is believed to be the major cleavage reaction in the collision-induced fragmentation of a phospholipid [39]. In a similar way, the prominent peaks in the spectra of B. sphaericus, Br. laterosporus, and E. coli HB101 can be identified to be those of PE with C28:0 lipid structure $(\mathrm{m} / \mathrm{z} 665)$, phosphotidylmethylethanolamine (PME) with C28:0 lipid structure $(\mathrm{m} / \mathrm{z} 679)$, and PE with C32:0 lipid structure $(\mathrm{m} / \mathrm{z}$ 691), respectively. Peaks in the $m / z 1300-1400$ (Table 2) can be seen to fragment into product ions that correspond to the peaks in the $m / z$ 500-750 region, indicating that the former are possible dimeric clusters (Figure $3 \mathrm{c}$ ), whose monomers occur in the range of $m / z 650-750$. We also observed peaks that have $\mathrm{m} / \mathrm{z}$ values three times the ones in the $m / z$ 650-750 region (data not shown). Such clusters can be explained when considering the structural arrangement of the bacterial lipid bilayer from where the phospholipids originate [40]. Phospholipids such as PE are known to constitute bacterial membranes, especially Gram negative ones [41]. Their amphipathic nature makes them amenable to relatively simple extraction procedures. Chloroform/methanol/water is a popular solvent mixture for their extraction. However, it is noteworthy that they dominate the spectral information even when a more polar solvent mixture such as aqueous acetonitrile is used, as is the case in the present study.

By contrast, the prominent peaks in the $m / z$ 800-950 region of the $B$. licheniformis spectrum show a different spectral pattern; there are four peaks observed at $\mathrm{m} / \mathrm{z}$ 888, 904, 916, and 932 that are not attributable to phospholipids. Similar $\mathrm{m} / \mathrm{z}$ values have been reported

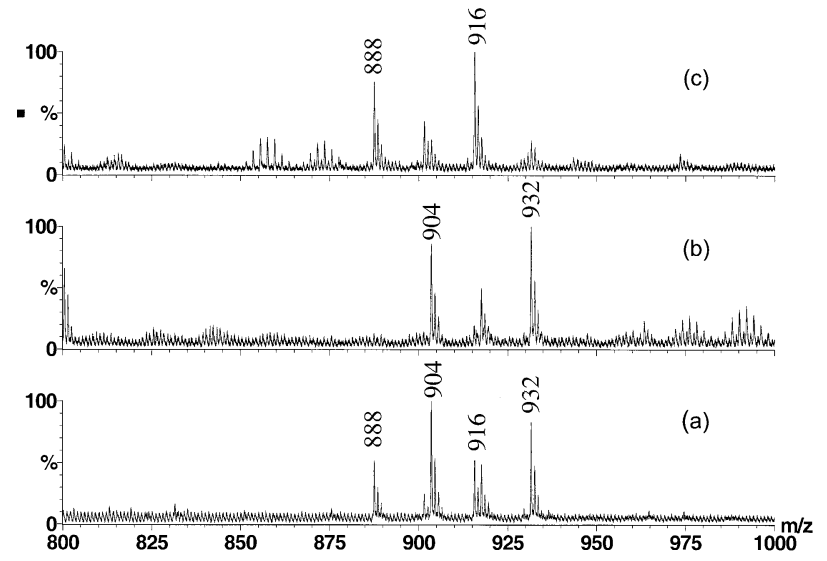

Figure 4. The four prominent peaks in the positive ion ESI mass spectra of B. licheniformis crude extract in the $m / z$ 800-1000 region, with (a) formic acid, (b) $\mathrm{KCl}$, and (c) $\mathrm{NaCl}$ in place of formic acid.

for glycolipids extracted from B. pumilus [42], where it was noted that the peaks originate from sodium and potassium adducts of diglycoglycerolipids. In order to ascertain if the peaks observed in the crude extract of $B$. licheniformis were also due to salt adducts, the mass spectra of the bacterial extract was obtained with sodium or potassium chloride $(2.5 \mathrm{mM})$ in place of formic acid, and compared with the spectrum obtained with formic acid alone (Figure 4). As can be seen from the figure, in the presence of sodium chloride an enhancement of the $\mathrm{m} / \mathrm{z} 888$ and $\mathrm{m} / \mathrm{z} 916$ peaks occurs, while in the presence of potassium chloride an enhancement of $\mathrm{m} / \mathrm{z} 904$ and 932 occurs with the complete suppression of $\mathrm{m} / \mathrm{z}$ 888. Carbohydrates are known to have a tendency to form salt adducts that are detected in ESI-MS in preference to protonated species. It is therefore possible that these peaks originate from glycolipids, which are known to occur in the membranes of Grampositive bacteria [41], and more particularly from dihexosyldiacylglycerolipids, known to occur in B. licheniformis [43]. The sodium and potassium cations otherwise probably originate from formic acid or acetonitrile, or from the glass bottles in which the solutions were stored. The peaks at $\mathrm{m} / \mathrm{z} 888$ and 916 are likely to be the sodium adducts, while those at $\mathrm{m} / \mathrm{z} 904$ and 932 the potassium adducts, as noted with glycolipids from B. pumilus [42]. The difference of 28 mass units between the peaks in each pair can be attributed to the difference in the fatty acid side chains attached to the glycerol backbone (Figure $3 b$ ).

Tandem mass spectrometry was carried out on these peaks to characterize their origins further. The most abundant product ions of the $\mathrm{m} / \mathrm{z} 888$ peak occurred at $\mathrm{m} / \mathrm{z} 645$ and 405 that have a mass difference with the precursor ion corresponding to the likely loss of fatty acid side chains (C14:0 units) (Figure $3 \mathrm{~b}$ ). The product ions observed at $\mathrm{m} / \mathrm{z} 365$ and 347 are likely to be the sodium adducts of the diglucosyl polar head group cleaved at two different sites (Figure $3 b$ ). These fragment peaks were also observed in the MS/MS spectrum 


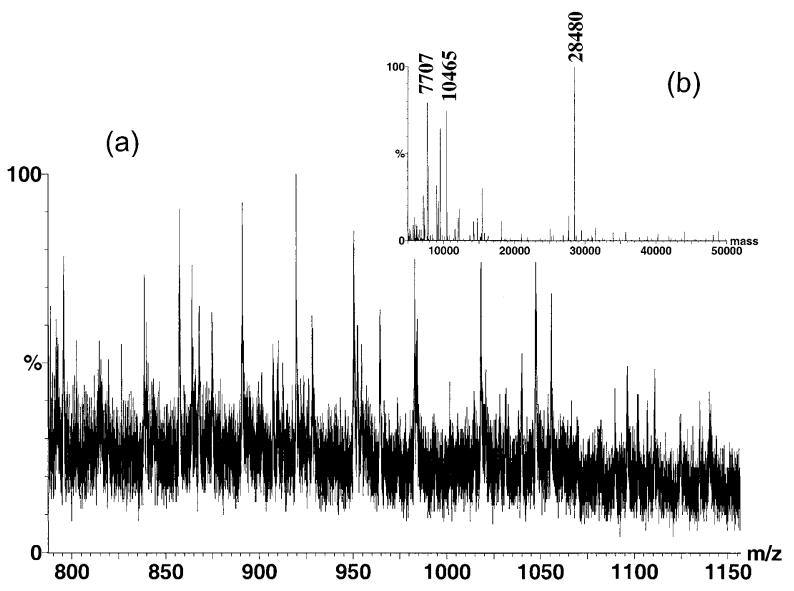

Figure 5. Charge distribution seen in the E. coli UB5201 crude extract FI-ESI mass spectrum and the deconvoluted Max Ent spectrum (inset).

of $m / z 916$ (Table 2). In a similar way, collision induced fragments of the potassium adduct $(\mathrm{m} / \mathrm{z} 904$ and 932) can also be noted. The peak at $\mathrm{m} / \mathrm{z} 689$ observed in the MS spectrum appears to have originated from the potassium adduct at $m / z$ 932, by a loss of one fatty acid side chain (corresponding to myristate-C14:0), although this was very weakly observed in the MS/MS of $\mathrm{m} / \mathrm{z}$ 932. The tandem mass spectrum of $\mathrm{m} / \mathrm{z} 689$ had two prominent peaks at $\mathrm{m} / \mathrm{z} 527$ and $\mathrm{m} / \mathrm{z} 365$ (Table 2), each differing from the other by 162 mass units, suggesting the subsequent loss of one glycosyl unit at a time, as schematized in Figure 3b. Peaks at intermediate $\mathrm{m} / \mathrm{z}$ values, such as 902 and 918 were also observed. These peaks differ from the ones at 888 and 904 respectively by 14 mass units, and are probably due to different fatty acid side chains. In addition, peaks attributable to phospholipids, at $\mathrm{m} / \mathrm{z}$ values of 665,705 and 524 , whose MS/MS spectra were identical to those in the other bacterial species, were also observed.

The charge distributions observed between $\mathrm{m} / \mathrm{z} 700-$ 1200 in the spectrum of B. sphaericus and E. coli UB5201 are likely to be due to multiply charged macromolecules, and since we were using a positive ion source these are likely to be proteinaceous in origin. In order to estimate the molecular weight of the macromolecule(s), the maximum entropy [44] routine supplied by Micro- mass (Max Ent I) was used. For the B. sphaericus charge distribution an estimate of $30-32 \mathrm{kDa}$ was obtained. It is possible that this is from a surface layer protein, as noted by us earlier [35]. The charge distribution in the $E$. coli UB5201 spectrum (Figure 5) is more complicated and is likely to be due to more than one protein. The estimates from Max Ent on six replicate spectra revealed at least three candidates with molecular weights of 28.5, 10.5, and $7.7 \mathrm{kDa}$; with $28.5 \mathrm{kDa}$ being most prominent (Figure 5). Further biochemical characterization is required to identify fully these proteins.

The prominent bacterial biomarkers observed in the MS spectra are summarized in Table 3. It is noteworthy that at least three classes of macromolecules are observed in the FI-ESI mass spectra, even though there was no prior analyte separation step involved and a relatively simple and rapid extraction procedure employed. The use of lipid based biomarkers for taxonomic purposes has to involve careful consideration of the growth conditions, as changes in the fatty acid composition to varying culture conditions would influence the spectral signal, as already observed with FAB-MS [39]. However, it is known from the FAB-MS literature (e.g., $[39,45])$ that neutral losses due to the loss of polar head groups from phospholipids and glycolipids can form a more stable basis for identification purposes. For example, in the present study $\mathrm{Br}$. laterosporus can be characterized by $\mathrm{N}$-methylethanolaminephosphate polar head, whilst loss of ethanolaminephosphate is observed with the other species. In addition, assessing the spectral information from microbial populations subjected to standardized growth conditions would minimize discrepancies due to changes in fatty acid composition and provide a more stable basis for spectral comparisons. This is why in the present case the cultures were all grown under identical conditions. Changes in lipid composition for a given species under different environmental conditions can, however, offer information about the metabolic status of the cell.

The observation of more than one macromolecular type in the spectral information offers a more stable basis for the use of these mass spectra for discriminatory purposes. It should also be noted that in addition to the peaks that were characterized by MS/MS, several

Table 3. Some prominent biomarkers $(\mathrm{m} / \mathrm{z}$ values and their likely buiomolecular origins) observed in the crude extract positive ion FI-ESI mass spectra of the representative strains of the five bacterial species studied

\begin{tabular}{|c|c|c|}
\hline \multirow[b]{2}{*}{ Bacteria } & \multicolumn{2}{|l|}{ Biomarker(s) } \\
\hline & $m / z$ & Biomolecular origin (likely) \\
\hline Br. laterosporus & $1370,1356,1342,716,679,665,524$ & Phospholipids \\
\hline \multirow[t]{2}{*}{ B. licheniformis } & $932,916,904,888,689,527$ & Glycolipids \\
\hline & $705,665,524$ & Phospholipids \\
\hline \multirow[t]{2}{*}{ B. sphaericus } & $1328,1342,665,524$ & Phospholipids \\
\hline & $1137,1024,960,905$ & Protein $(30-32 \mathrm{kDa})$ \\
\hline \multirow[t]{2}{*}{ E. coli UB5201 } & $1422,1408,1394,1380,719,705,691,665,577,564,550$ & Phospholipids \\
\hline & $1096,1056,1047,1018,983,964,950,928,920,891,864,858,839$ & Protein(s) $(28,10.4,7.7 \mathrm{kDa})$ \\
\hline E. coli HB101 & $1408,1394,1380,705,691,665,564,550,524$ & Phospholipids \\
\hline
\end{tabular}


others in the low mass end of the spectrum below $\mathrm{m} / \mathrm{z}$ 500 were observed. Although collision induced fragments of the high mass peaks $(>m / z 500)$ would contribute to the signals at the low mass end, these are likely to be superceded by low molecular weight metabolic biomarkers, particularly at low cone potentials, contributing to the overall spectral information for bacterial discrimination.

The bacterial cell is a complex biochemical entity composed of many proteins, carbohydrates, lipids, and other macromolecules. However, only a portion of the macromolecular milieu is captured by current mass spectrometric techniques. With ESI-MS of unfractionated cell extracts, employment of LC offers the capability to increase the information content, as has been shown by Krishnamurthy and colleagues [15], due to separation of the analyte fractions and resultant minimization of ion suppression effects. Alternatively, online microdialysis [30] can be employed to maximize information content. However, although an LC or microdialysis step can be included in the analysis scheme, it is unlikely that they will be amenable for high-throughput automated analysis. That information rich mass spectra can be produced even with the simple FI-ESI-MS approach described here bodes well for the development of a rapid bacterial characterization system. In addition, the possibility of further characterizing the peaks with MS/MS, and the availability of nano-electrospray techniques offers greater potential for sensitive rapid highthroughput bacterial identification.

\section{Stability of Extracts for Automated FI-ESI MS}

Any automated method would require that the samples are stable over the duration of the analysis. Stability is an important consideration, given the fact that the analytes are in the liquid phase. In order to investigate the stability of the crude extracts, the extracts were kept either at room temperature $\left(20^{\circ} \mathrm{C}\right)$ or refrigerated at $4{ }^{\circ} \mathrm{C}$, and were injected into the mass spectrometer at different time intervals $(t=0 \mathrm{~h}, 5 \mathrm{~h}$, or 16-24 h). Figure 6 shows the spectra of a representative bacterial strain; E. coli HB101 acquired at a cone potential of $30 \mathrm{~V}$, under the five different sample storage conditions detailed above. Visual inspection of the spectra shows very little difference between the different storage conditions, and the spectra appear to be reproducible under all the storage conditions tested. As requested by one of the referees, Table 4 lists the precision of the peak positions for representative peaks across the spectral range for three of the five bacterial species studied, for both within replicate measurements (biological replicates) and between the different storage conditions. As can be seen from the table the peak positions are stable and comparable for all measurements made. However, such an assessment gives an indication of stability with respect to peak positions only. It is possible that some peaks may appear or disappear or may vary in relative

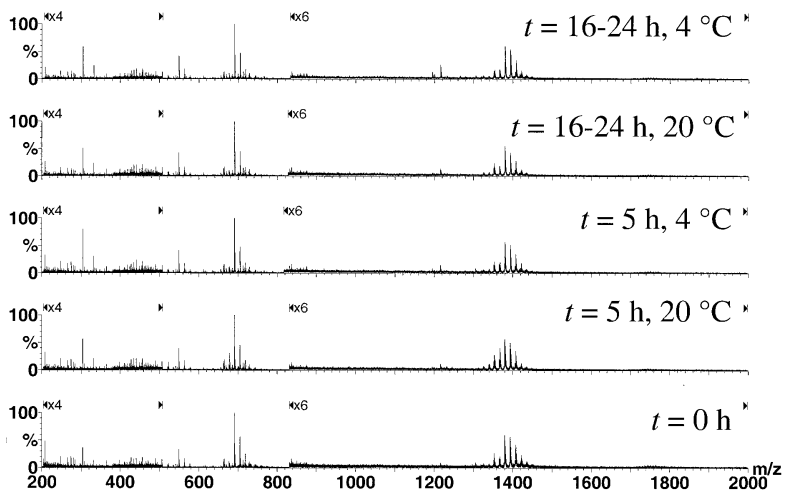

Figure 6. Typical positive ion ESI mass spectra of E. coli HB101, obtained at a cone potential of $30 \mathrm{~V}$, showing stability of the crude extracts over time $(t)$. Selected regions of the spectrum are magnified (with the magnification factor indicated where relevant), for ease of visualization.

intensity between the different storage conditions, and this needs to be addressed.

In order to assess the repeatability and stability of the total quantitative spectral information content for all the five bacterial strains, chemometric analysis was done on the replicate spectra, as detailed in the experimental section. The application of PCA and analysis of the resultant information by hierarchical cluster analysis is one approach to obtain global information and thereby observe the relative similarity between the spectra, and has been shown to be useful in the analysis of MS and vibrational spectroscopic data [37, 38]. Accordingly, PCA was performed on the variance corrected average spectra, and the first few PC scores (typically five) that

Table 4. Precision of representative peak positions in the ESI mass spectra of three bacterial species, showing repeatability of the spectral information

\begin{tabular}{|c|c|c|c|}
\hline \multirow[b]{2}{*}{ Bacteria } & \multirow{2}{*}{$\begin{array}{l}\text { Representative } \\
\text { peak positions } \\
\text { (average } \mathrm{m} / \mathrm{z} \text { ) }\end{array}$} & \multicolumn{2}{|c|}{ Relative SD $(\%)$} \\
\hline & & $\begin{array}{l}\text { Between } \\
\text { replicates }^{\mathrm{b}}\end{array}$ & $\begin{array}{c}\text { Between } \\
\text { treatments }^{c}\end{array}$ \\
\hline \multirow[t]{5}{*}{ E. coli UB5201 } & 304.31 & 0.007 & 0.002 \\
\hline & 563.51 & 0.001 & 0.002 \\
\hline & 690.53 & 0.002 & 0.002 \\
\hline & 704.54 & 0.001 & 0.003 \\
\hline & 1394.07 & 0.001 & 0.005 \\
\hline \multirow[t]{6}{*}{ B. licheniformis } & 214.05 & 0.008 & 0.001 \\
\hline & 523.49 & 0.002 & 0.003 \\
\hline & 887.60 & 0.003 & 0.003 \\
\hline & 903.57 & 0.001 & 0.003 \\
\hline & 915.63 & 0.002 & 0.003 \\
\hline & 931.60 & 0.002 & 0.003 \\
\hline \multirow[t]{5}{*}{ Br. laterosporus } & 339.17 & 0.003 & 0.002 \\
\hline & 523.47 & 0.001 & 0.004 \\
\hline & 678.50 & 0.000 & 0.004 \\
\hline & 716.47 & 0.002 & 0.003 \\
\hline & 1356.03 & 0.002 & 0.003 \\
\hline
\end{tabular}

aSD - Standard Deviation

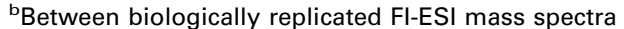

${ }^{\mathrm{C} B e t w e e n ~ d i f f e r e n t ~ s t o r a g e ~ o p t i o n s ~}$ 


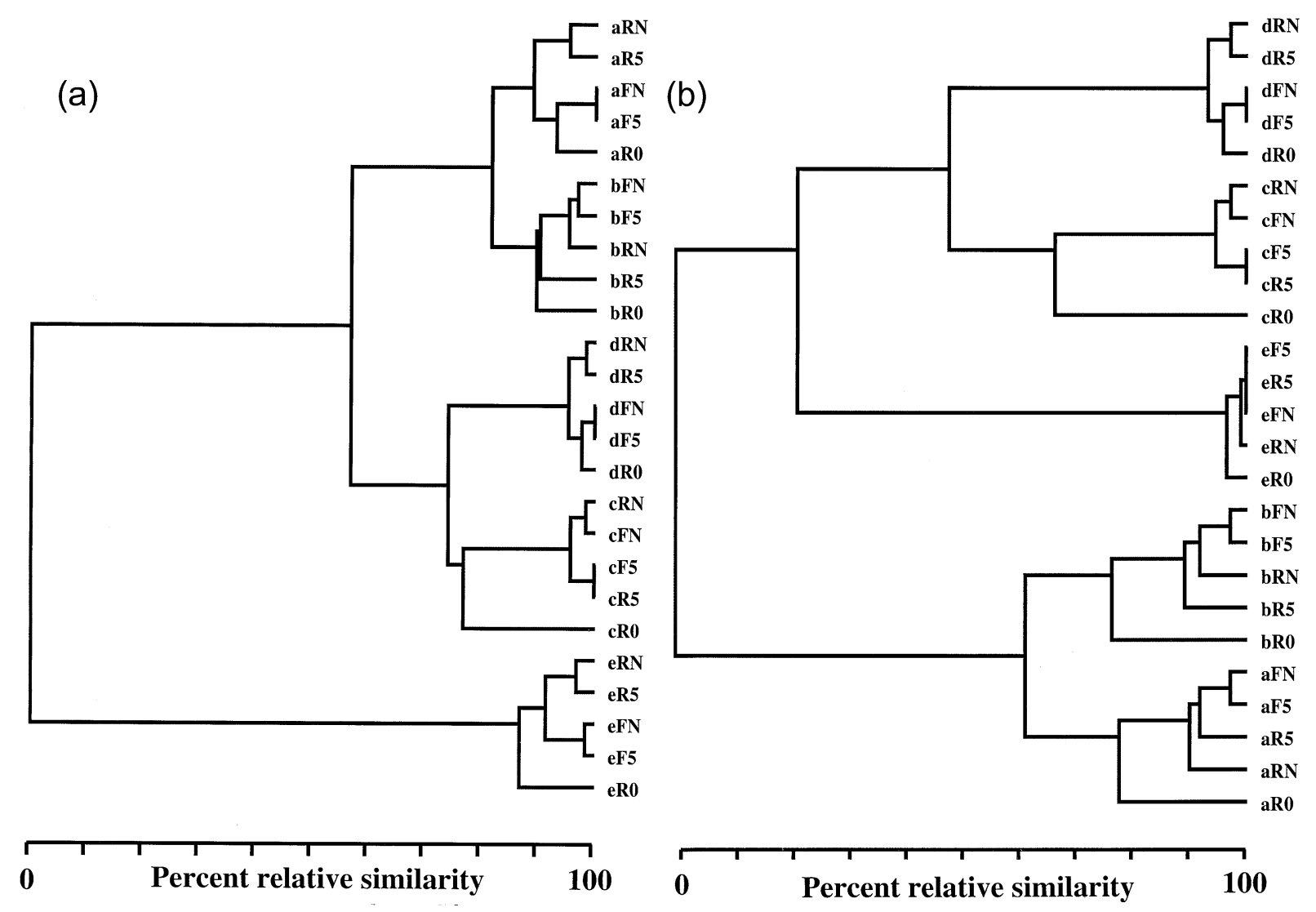

Figure 7. Clustering of PC scores derived from the positive ion ESI mass spectra of crude extracts for the five bacterial strains, acquired at a cone potential of (a) $30 \mathrm{~V}$ and (b) $70 \mathrm{~V}$, showing stability of the crude extracts over time. The first letter in each label indicates the bacterial strain [a-e, (Table 1)]; the second letter indicates the storage temperature, $\mathrm{R}=$ room temperature, $\mathrm{F}=4{ }^{\circ} \mathrm{C}$; and the third the duration of storage, $0=$ after $0 \mathrm{~h}, 5=$ after $5 \mathrm{~h}, \mathrm{~N}=$ after $16-24 \mathrm{~h}$.

explained at least $95 \%$ of the total variance in the two data sets were used to construct dendrograms for the two cone potentials (Figure 7). As can be seen, for both the cone potentials, the clustering is such that the spectra from each bacterial strain are grouped together. The clustering pattern also reflects the microbiological difference between these bacteria; the two E. coli strains (a and b) cluster together and away from the others, as do the two Bacillus strains (c and d), whilst Br. laterosporus (e) clusters separately. This classification was observed at both the cone potentials tested. Examination of the subclustering patterns for each bacterium reveals (1) that in all cases the $0 \mathrm{~h}$ sample clusters away from the others, (2) that the samples at each of the storage temperatures cluster together, at least for the spectra of E. coli HB101 (a), B. licheniformis (d), and Br. laterosporus (e), acquired at a cone potential of $30 \mathrm{~V}$ (Figure 7a), and (3) that for $B$. sphaericus (c), the clustering seems to be related to the time of storage. Of course, cluster analyses enable one to assess only the relative similarity between the spectra and so should be carefully interpreted. Based on the cluster analyses and a close inspection of the representative spectra (Figure 6), the degree of simi- larity between the spectra seems to be greater than the differences, even for the two E. coli strains. Since the best similarity between the spectra was from those stored at $4{ }^{\circ} \mathrm{C}$ it is likely that maintaining the samples at $4{ }^{\circ} \mathrm{C}$ would enable sufficient reproducibility for discriminatory purposes. However, close control of sample storage and analysis conditions may be required for the discrimination of even more closely related strains. Cluster analysis carried out on non-averaged replicate spectra also showed a very similar result (data not shown). The spectra of biological replicates clustered together, suggesting that the spectra are indeed biologically repeatable (i.e., a given microorganism gives the same spectra consistently when grown under a defined set of conditions). For ease of visualization, only the results of the average spectra are shown in the dendrograms.

The spectral repeatability observed here compared to the concerns over the MALDI-MS analysis of whole bacterial cells $[14,17,20,21]$ and the sensitivity achievable, reportedly an order of magnitude better compared to MALDI-MS [15], suggests that ESI-MS can be advantageous over MALDI-MS as well as complementary to it for microbial characterization. 

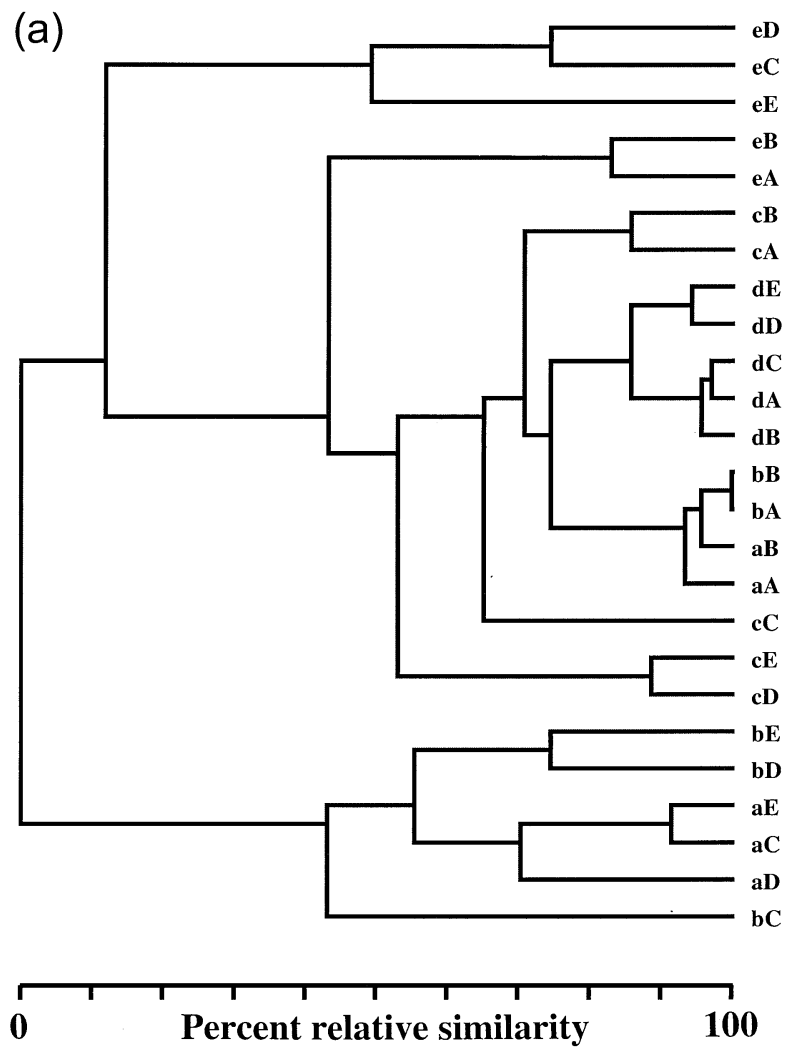

(b)

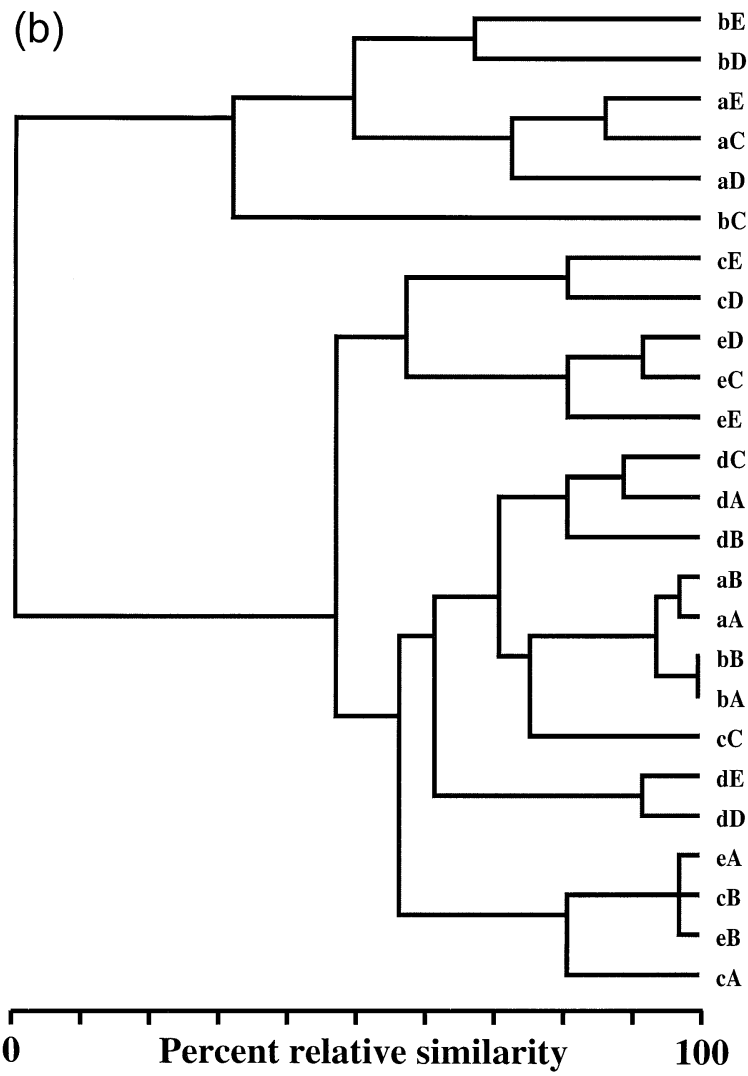

Figure 8. Clustering of PC scores derived from the positive ion ESI mass spectra of the five different supernatants (A-E), for the five bacterial strains (a-e), acquired at a cone potential of (a) $30 \mathrm{~V}$, and (b) $70 \mathrm{~V}$, showing the relative similarity between the treatments.

\section{Solvent Composition and Spectral Information}

The solvent (aqueous acidic acetonitrile) in which the bacteria were suspended in the present study is known to assist the ESI process, has been commonly employed for MS of biomacromolecules [46, 47], and has been used in LC-ESI-MS [31] and MALDI-MS investigations $[15,20,48,49]$ for microbial characterization. However, little is known about the effect of solvent composition on the extraction process and in turn the spectral information. In MALDI-MS investigations, Krishnamurthy and colleagues [15] have reported that the acidity of the solvent causes partial lysis of the cells releasing proteins and peptides. By contrast, other workers $[20,50]$ have shown that there is little evidence of cellular damage by lysis and that the signals observed are those of cell wall and/or membrane-associated proteins [48, 49]. More recently, a protein data base search has revealed that the proteins exuded from such treatments, at least with $E$. coli $\mathrm{K} 12$, can be traced to the cytosol, suggesting cell lysis [18]. Clearly, the solvent used has to be carefully investigated to understand the effect it has on the bacterial cells.

To gain a better understanding of the effect the solvent composition has on the extraction, in terms of the information content in the mass spectra, the washed bacterial cells were suspended in each component in turn, vortex mixed, then centrifuged, and finally the supernatant was mixed with the remaining component(s), before MS. Five supernatants (A-E) were obtained for each bacterium in triplicates and analyzed by FI-ESI-MS. As detailed in Figure 1, supernatant A shows the effect of water alone, B that of formic acid, C that of acetonitrile, D that of water and acetonitrile (aqueous acetonitrile), and E, which is the control, the effect of all the components (acidic aqueous acetonitrile). As performed above, the variance-corrected average spectra were subjected to PCA and the PC scores used to construct a dendrogram, in order to obtain global information. Figure 8 shows the dendrograms for the spectra acquired at the two cone potentials of $30 \mathrm{~V}$ and $70 \mathrm{~V}$. In all cases, it can be seen that the spectra of supernatants D and E cluster together, although in some cases $\mathrm{C}$ is also included in the cluster. This strongly suggests that the effect of acetonitrile on the bacterial cells contributes significantly to the spectral information. It can also be observed that the clustering pattern for the spectra of these supernatants $(\mathrm{D}, \mathrm{E}$, and $C$ ) relates to the microbiological diversity between the bacteria, whilst this is not the case with the spectra of supernatants A or B. A and B cluster away from the $C, D$, and $E$ group for all the five bacteria at both the cone potentials indicating that water 


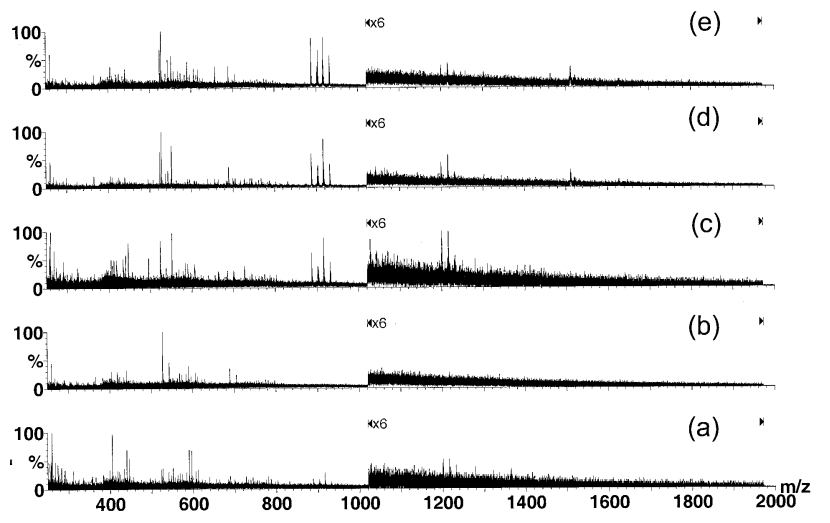

Figure $9(\mathrm{a}-\mathrm{e})$. Typical positive ion ESI mass spectra of the five supernatants obtained as detailed in Figure 1, for B. licheniformis, acquired at a cone potential of $70 \mathrm{~V}$. Selected regions of the spectrum are magnified (with the magnification factor indicated where relevant), for ease of visualization.

whether acidic or not is not as effective in releasing cellular components useful for discriminatory purposes. An inspection of Figure 9, which for illustrative purposes shows the spectra of the five supernatants for B. licheniformis $(70 \mathrm{~V})$, indicates that some prominent peaks observed in the spectra of supernatants C, D, and E are absent from those of A and B. The relative intensities of the peaks are also lower (as seen from greater noise) in the spectra of A and B, compared to those of $\mathrm{C}, \mathrm{D}$, and $\mathrm{E}$, indicating that acetonitrile contributes significantly to the extraction of bacterial metabolites that can be useful for discriminatory purposes. A similar result was obtained when trifluoroacetic acid was used instead of formic acid, suggesting that the solvent rather than the acid used may have a greater effect on the extraction of metabolites useful for discriminatory purposes. Optimization of the extraction conditions, by investigating the organic solvent used in the extraction procedure, might further enable one to extract maximal ESI-MS information, useful for rapid bacterial identification, and this will be an area of future study.

\section{Conclusions}

FI-ESI-MS of crude cell-free extracts without prior anylate separation was investigated as a highthroughout method for the characterization of bacteria. The spectra were information rich and useful for discriminatory purposes. MS/MS on prominent peaks revealed that the spectral information was dominated by phospholipids; however, two other macromolecular types, namely glycolipids and proteins were also observed. The spectra were reproducible and stable even when the extracts were stored at room temperature for up to $24 \mathrm{~h}$. Acetonitrile was found to contribute significantly to the information content of the mass spectra by enhancing the extraction process. The reproducible detection of more than one macromolecular type in a single crude extract spectrum without the need for prior analyte separation suggests that it is possible to obtain mass spectral information that can be used for bacterial characterization, using FI-ESI-MS. We believe that this approach has potential application within highthroughput screening (HTS) programs for microbial identification since it requires little sample preparation, is automated, and rapid.

\section{Acknowledgments}

The authors thank the Engineering and Biological Systems Committee of the UK BBSRC for financial support. They are indebted to Mr. Jim Heald for his advice with ESI-MS, and are grateful to Dr. Niall Logan for providing the Bacillus and Brevibacillus strains. They are also grateful to the referees of this paper for their useful comments and suggestions.

\section{References}

1. Altekruse, S. F.; Cohen, M. L.; Swerdlow, D. L. Emerging Foodborne Diseases. Emerg. Infect. Dis. 1997, 3, 285-293.

2. Magee, J.T. In Topley and Wilson's Microbiology and Microbial Infections; Collier, L., Ed.; Arnold: London, 2000; pp 45-64.

3. Devlin, J. P. High-Throughput Screening: The Discovery of Bioactive Substances. Marcel Dekker: New York, 1997.

4. Fenselau, C. Mass Spectrometry for the Characterization of Microorganisms. American Chemical Society: Washington DC, 1994.

5. Goodacre, R.; Kell, D. B. Pyrolysis Mass Spectrometry and Its Applications in Biotechnology. Cur. Opin. Biotechnol. 1996, 7, 20-28.

6. Magee,, J. T. In: Goodfellow, M.; O'Donnell, A.G., Eds.; Academic Press: London, 1993; pp 383-427.

7. Cotter, R. J. Plasma Desorption Mass Spectrometry-Coming of Age. Anal. Chem. 1988, 60, 781.

8. Drucker,, D. B. In Fenselau, C, Ed. Mass Spectrometry for the Characterization of Microorganisms, Vol. DXLI. American Chemical Society: Washington DC, 1994; 18-35.

9. Heller, D. N.; Cotter, R. J.; Fenselau, C. Profiling of Bacteria by Fast Atom Bombardment Mass Spectrometry. Anal. Chem. 1987, 59, 2806-2809.

10. Roepstorff, P. Mass spectrometry in Protein Studies from Genome to Function. Cur. Opin. Biotechnol. 1997, 8, 6-13.

11. Yates, J. R. Mass Spectrometry-from Genomics to Proteomics. Trends Genet. 2000, 16, 5-8.

12. Black, G. E.; Fox, A. In Snyder, P.A., Ed. Biochemical and Biotechnological Applications of Electrospray Ionization Mass Spectrometry, Vol. DCXIX. American Chemical Society: Washington DC, 1996; 81-105.

13. van Baar, B. L. M. Characterization of Bacteria by MatrixAssisted Laser Desorption/Ionization and Electrospray Mass Spectrometry. FEMS Microbiol. Rev. 2000, 24, 193-219.

14. Dalluge, J. J. Mass Spectrometry for Direct Determination of Proteins in Cells: Applications in Biotechnology and Microbiology. Fres. J. Anal. Chem. 2000, 366, 701-711.

15. Krishnamurthy, T.; Rajamani, U.; Ross, P. L.; Jabhour, R.; Nair, H.; Eng, J.; Yates, J.; Davis, M. T.; Stahl, D. C.; Lee, T. D. Mass Spectral Investigations on Microorganisms. J. Toxicol. Toxin Rev. 2000, 19, 95-117.

16. Claydon, M. A.; Davey, S. N.; Edwardsjones, V.; Gordon, D. B. The Rapid Identification of Intact Microorganisms Using Mass Spectrometry. Nat. Biotechnol. 1996, 14, 1584-1586.

17. Lay, J. O. J. MALDI-TOF Mass Spectrometry and Bacterial Taxonomy. Trends Anal. Chem 2000, 19, 507-516. 
18. Ryzhov, V.; Fenselau, C. Characterization of the Protein Subset Desorbed by MALDI from Whole Bacterial Cells. Anal. Chem. 2001, 73, 746-750.

19. Demirev, P. A.; Ho, Y. P.; Ryzhov, V.; Fenselau, C. Microorganism Identification by Mass Spectrometry and Protein Database Searches. Anal. Chem. 1999, 71, 2732-2738.

20. Domin, M. A.; Welham, K. J.; Ashton, D. S. The Effect of Solvent and Matrix Combinations on the Analysis of Bacteria by MALDITOF MS. Rapid Commun. Mass Spectrom. 1999, 13, 222-226.

21. Wang, Z. P.; Russon, L.; Li, L.; Roser, D. C.; Long, S. R. Investigation of Spectral Reproducibility in Direct Analysis of Bacteria Proteins by Matrix-Assisted Laser Desorption/Ionization Time-of-Flight Mass Spectroscopy. Rapid Commun. Mass Spectrom. 1998, 12, 456-464.

22. Saenz, A. J.; Petersen, C.E.; Valentine, N. B; Gantt, S. L.; Jarman, K. H.; Kingsley, M. T.; Wahl, K. L. Reproducibility of Matrix-Assisted Laser Desorption/Ionization Time-of-flight Mass Spectrometry for Replicate Bacterial Culture Analysis. Rapid Commun. Mass Spectrom. 1999, 13, 1580-1585.

23. Arnold, R. J.; Reilly, P. Fingerprint Matching of E. coli strains with Matrix-Assisted Laser Desorption/Ionization Time-ofFlight Mass Spectrometry of Whole Cells Using a Modified Correlation Approach. Rapid Commun. Mass Spectrom. 1998, 12, 630-636.

24. Smith, P. B. W.; Snyder, P.; Harden, C. S. Characterization of Bacterial Phospholipids by Electrospray-Ionization Tandem Mass Spectrometry. Anal. Chem. 1995, 67, 1824-1830.

25. Black, G. E.; Snyder, A. P.; Heroux, K. S. Chemotaxonomic Differentiation Between theBacillus cereus Group andBacillus subtilis by Phospholipid Extracts Analyzed with Electrospray Ionization Tandem Mass Spectrometry. J. Microb. Methods 1997, 28, 187-199.

26. Fang, J.; Barcelona, M. J. Structural Determination and Quantitative Analysis of Bacterial Phospholipids Using Liquid Chromatography Electrospray Ionization Mass Spectrometry. J. Microb. Methods 1998, 33, 23-35.

27. Li, J.; Thibault, P.; Martin, A.; Richards, J. C.; Wakarchuk, W. W.; van der Wilp, W. Development of an On-Line Preconcentration Method for the Analysis of Pathogenic Lipopolysaccharides Using Capillary Electrophoresis-Electrospray Mass Spectrometry-Application to Small Colony Isolates. J. Chromatogr. A 1998, 817, 325-336.

28. Gibson, B. W.; Phillips, N. J.; John, C. M.; Melaugh, W. Lipooligosaccharides in pathogenic Haemophilus and Neisseria Species-Mass Spectrometric Techniques for Identification and Characterization. ACS Symp. Series 1994, 541, 185-202.

29. Wunschel, D. S.; Fox, K. F.; Fox, A.; Nagpal, M. L.; Kim, K.; Stewart, G. C.; Shahgholi, M. Quantitative Analysis of Neutral and Acidic Sugars in Whole Bacterial Cell Hydrolysates Using High-Performance Anion-Exchange Liquid Chromatography Electrospray Ionization Tandem Mass Spectrometry. J. Chromatogr. A 1997, 776, 205-219.

30. Liu, C. L.; Hofstadler, S. A.; Bresson, J. A.; Udseth, H. R.; Tsukuda, T.; Smith, R. D.; Snyder, A. P. On Line Dual Microdialysis with ESI-MS for Direct Analysis of Complex Biological Samples and Microorganism Lysates. Anal. Chem. 1998, 70, 1797-1801.

31. Krishnamurthy, T.; Davis, M. T.; Stahl, D. C.; Lee, T. D. Liquid Chromatography/Microspray Mass Spectrometry for Bacterial Investigations. Rapid Commun. Mass Spectrom. 1999, 13, $39-49$.

32. Despeyroux, D.; Phillpotts, R.; Watts, P. Electrospray Mass Spectrometry for Detection and Characterization of Purified Cricket Paralysis Virus (CrPV). Rapid Commun. Mass Spectrom. 1996, 10, 937-941.

33. Siuzdak, G. Probing Viruses with Mass Spectrometry. J. Mass Spectrom. 1998, 33, 203-211.
34. Goodacre, R.; Heald, J. K.; Kell, D. B. Characterization of Intact Microorganisms Using Electrospray Ionization Mass Spectrometry. FEMS Microbiol. Letters 1999, 176, 17-24.

35. Vaidyanathan, S.; Rowland, J. J.; Kell, D. B.; Goodacre, R. Discrimination of Aerobic Endospore-Forming Bacteria Via Electrospray-Ionization Mass Spectrometry of Whole Cell Suspensions. Anal. Chem. 2001, 73, 4134-4144.

36. Moini, M.; Jones, B. L.; Rogers, R. M.; Jiang, L. F. Sodium Trifluoroacetate as a Tune/Calibration Compound for Positive- and Negative-Ion Electrospray Ionization Mass Spectrometry in the Mass Range of. J. Am. Soc. Mass Spectrom. 1998, 9, 977-980.

37. Goodacre, R.; Timmins, É. M.; Burton, R.; Kaderbhai, N.; Woodward, A. M.; Kell, D. B.; Rooney, P. J. Rapid Identification of Urinary Tract Infection Bacteria Using Hyperspectral, Whole Organism Fingerprinting and Artificial Neural Networks. Microbiol. 1998, 144, 1157-1170.

38. Goodacre, R.; Shann, B.; Gilbert, R. J.; Timmins, É. M.; McGovern, A. C.; Alsberg, B. K.; Kell, D. B.; Logan, N. A. Detection of the Dipicolinic Acid Biomarker in Bacillus Spores Using CuriePoint Pyrolysis Mass Spectrometry and Fourier Transform Infrared Spectroscopy. Anal. Chem. 2000, 72, 119-127.

39. Cole, M. J.; Enke, C. G. In Fenselau, C, Ed. Mass Spectrometry for the Characterization of Microorganisms, Vol. DXLI. American Chemical Society: Washington DC, 1994; pp 36-61.

40. Burnell, E.; Alphen, L. V.; Verkleij, A.; Kruijff, B. D. ${ }^{31}$ P Nuclear Magnetic Resonance and Freeze-Fracture Electron Microscopy Studies on Escherichia coli I: Cytoplasmic Membrane and Total Phospholipids. Biochim. Biophys. Acta 1980, 597, 492-501.

41. Lechevalier, M. P. Lipids in Bacterial Taxonomy-A Taxonomist's View. CRC Crit. Rev. Microbiol. 1977, 5, 109-210.

42. Wang, W.; Liu, Z.; Ma, L.; Hao, C.; Liu, S.; Voinov, V. G.; Kalinovskaya, N. I. Electrospray Ionization Multiple-Stage Tandem Mass Spectrometric Analysis of Diglycosyldiacylglycerol Glycolipids from the Bacteria. Bacillus pumilus. Rapid Commun. Mass Spectrom. 1999, 13, 1189-1196.

43. Fischer, W.; Nakano, M.; Laine, R. A.; Bohrer, W. On the Relationship between Glycerophosphoglycolipids and Lipoteichoic Acids in Gram-Positive Bacteria I: The Occurrence of Phosphoglycolipids. Biochim. Biophys. Acta 1978, 528, 288-297.

44. Skilling, J. Maximum Entropy and Bayesian Methods; In Skilling, J., Ed.; Kluwer Academic Publishers: Dordtrecht, 1989; pp $45-52$.

45. Heller, D. N.; Murphy, C. M.; Cotter, R. J.; Fenselau, C.; Uy, O. M. Constant Neutral Loss Scanning for the Characterization of Bacterial Phospholipids Desorbed by Fast Atom-Bombardment. Anal. Chem. 1988, 60, 2787-2791.

46. Snyder, A. P. Electrospray: A Popular Ionization Technique for Mass Spectrometry. American Chemical Society: Washington DC, 1996.

47. Cole, R. B. Electrospray Ionization Mass Spectrometry: Fundamentals, Instrumentation, and Applications. Wiley: New York, 1997.

48. Dai, Y.; Li, L.; Roser, D. C.; Long, S. R. Detection and Identification of Low-Mass Peptides and Proteins from Polvent Puspensions of Escherichia coli by High Performance Liquid Chromatography Fractionation and Matrix-Assisted Laser Desorption/Ionization Mass Spectrometry. Rapid Commun. Mass Spectrom. 1999, 13, 73-78.

49. Holland, R. D.; Duffy, C. R.; Rafii, F.; Sutherland, J. B.; Heinze, T. M.; Holder, C. L.; Voorhees, K. J.; Lay, J. O. Identification of Bacterial Proteins Observed in MALDI TOF Mass Spectra from Whole Cells. Anal. Chem. 1999, 71, 3226-3230.

50. Welham, K. J.; Domin, M. A.; Scannell, D. E.; Cohen, E.; Ashton, D. S. The Characterization of Micro-Organisms by MALDI-TOF MS. Rapid Commun. Mass Spectrom. 1998, 12, 176-180. 